\title{
Bridging research and dissemination in the CoViD-19 era: a WebGIS dashboard for the Autonomous Province of Trento (Italy)
}

\author{
Nicola Gabellieri ${ }^{\mathrm{a}}$, Francesco Geri ${ }^{\mathrm{b}}$, Andrea Marco Raffaele Pranzo ${ }^{\mathrm{a}^{*}}$, Paolo Zatelli ${ }^{\mathrm{b}}$ \\ ${ }^{a}$ University of Trento, Department of Humanities, Geo-cartographic Centre of Study and Documentation - GeCo, \\ nicola.gabellieri@unitn.it,andrea.pranzo@unitn.it, \\ ${ }^{b}$ University of Trento, Department of Civil, Environmental and Mechanical Engineering, geri.francesco@gmail.com \\ paolo.zatelli@unitn.it \\ * Corresponding author
}

\begin{abstract}
The paper presents an ongoing project devoted to the study, the analysis and the representation of epidemiological data related to CoViD-19 spread in the territory of the Province of Trento (Italy), both for scientific and communication purposes. In this broader context, the construction of a digital cartography tool as a WebGIS to allow local communities understanding of epidemiological spread is presented. Data have been supplied by the local Provincial Health Authority; statistic have been processed in order to develop municipality scale vector polygonal coropleth and point maps in order to show affected, health and death rate distribution. A timeline allows the representation of changes and dynamics from Spring 2020 to the current date. The database provides "on-the-fly" data to the production scripts of maps and time charts. These scripts querying the database produce a geographic file in the geojson standard interchange format. This file is read by the javascript scripts based on the leaflet libraries for the production of the final maps. In a similar process, scripts based on the chart.js library produce the graph of the data temporal variation, automatically reading dates and interval time of analysis. A custom procedure was developed to allow the periodic update of the dataset. New information is added to the database by uploading an external spreadsheet. The study presents the methodology to develop and assess the WebGIS for managing, visualize and analyse Coronavirus diffusion. Future implementation of the WebGIS will expand the used data and allow the comparison with social and environmental factors.
\end{abstract}

Keywords: WebGIS, CoViD-19, health geography, dissemination

\section{Introduction}

In December 2019 a severe human respiratory disease, afterwards named CoViD-19, emerged in China (Lu et al., 2020), and rapidly became the worst planetary health emergency probably since the 1918 "Spanish Flu", affecting any country in the world just in few months. According to the World Health Organization guidelines, transparent communication is one of the main strategic axes in epidemic fighting and controlling, together with data analysis and health service management (WHO, 2005). Within the framework of epidemiological geography, thematic cartography has always been the main instrument for the collection and dissemination of health

1 According to a classical definition, a dashboard is a "visual displays of the most important information needed to achieve one or more objectives; consolidated and arranged on a single screen so information can be monitored at a glance" (Few, $2006,34)$. Such definition does not involve the presence of datasets, as well as for their deeper spatial analysis (Carroll et al., 2014). Indeed, the steady shift towards a data-rich environment that research in applied geography recently experienced (Miller, Goodchild, 2015) strongly enhanced the need to outline effective and functional tools able to collect, manage, analyse and display the growingly available georeferenced data in any field of spatially-based studies. Among them, dashboards became one of the most popular and effective tools for connecting large public to scientific results and official data communication ${ }^{1}$.

\subsection{Aims}

The paper presents an applied geography research aimed at the development of a WebGIS for the spatial and

cartographies; despite this, the large number of dashboards devoted to the pandemic monitoring arisen during 2020 and 2021 are strictly linked with static or dynamic maps (Boulos, Geraghty, 2020; Guallart Moreno, 2020; Dai Prà et al, 2020). 
diachronic representation of the Autonomous Province of Trento [Provincia Autonoma di Trento] epidemiological data. Such research is part of a broader project that aims to experiment the use of spatial approaches and cartographic tools for the representation and analysis of health, social and environmental data for the understanding of the epidemic phenomenon in fieri and ex post (Brunialti et al., 2020; Dai Prà et al., 2020).

\subsection{Epistemological and methodological framework}

Since the 1990s, GIS have progressively established themselves as one of the most effective data management and analysis tools for all research disciplines interested in the study of spatial and territorial phenomena (Aitken, 2002; Cope, Elwood, 2009). More recently, GIS stood out as emergency monitoring tools and digital map viewers aimed at fostering the correct understanding of spatiallyrelated dynamics. Even before the pandemic, the use of territorial information systems in the field of medical geography with both analytical and communicative values was already consolidated (Palagiano, 1998; Carroll et al., 2014; Crooks et al., 2018). During the present pandemic, the GIS-driven dissemination of health data attained an extraordinary popularity, starting from the earliest pioneering models (Dong et al., 2020) up to the several ensuing experiences of epidemiological dashboards (Dagnino et al., 2020; Rossman et al., 2020; Gao et al., 2020; Berry et al., 2020; Hohl et al., 2020).

At the beginning of May 2020, Ivan Franch-Pardo et al. (2020) surveyed a total of 63 scientific articles published in academic journals and dedicated to various epistemological and methodological geographical and / or cartographic aspects of the epidemic; essays ranging from the local to the global scale, and which have been classified into five categories, according to the greater relevance accorded to spacetime analyzes of the epidemic course, to web-based cartography and volunteering geographical information, to automatic data mining systems and big data analysis, and environmental variables and their relationships with the spread of the disease. In particular, web-based cartography emerged as one of the primary types of response of the academic environment to the urgency of immediate communication of the pandemic risk at the global and national level (Dai Prà et al., 2020; Podda, Scanu, 2020; Guallart Moreno, 2020).

In fact, in last years the increasing diffusion of digital cartography have intertwined with the implementation of the internet, involving the development of increasingly easy-to-use GIS services for the collection and distribution of geographical data. With WebGIS and CloudGIS solutions, "GIS has now been able to make its concepts more open, accessible and mobile to all, thus facilitating notions such as the democratization of space data, open accessibility and the effective dissemination" (Dragićević, 2004, 79); and recently the areas in which the activation of WebGIS portals is proposed as a vehicle for data distribution and interface between users are increasingly spreading, and were even explicitly acknowledged in the EU operational programs (Evangelidis et al., 2018). In fact, a WebGIS can enhance and facilitate cartographic elaboration at least in three main directions: 1) spatial data dissemination, 2) spatial data geovisualisation, 3) spatial data processing and analysis. While in the first phase of the epidemic spread the cartographic representation was developed to satisfy the need of instant information, actually dashboards and websites are exploring new directions for promoting transparency of decision making, communities' involvement, risk awareness and people motivation (Boulos, Geraghty, 2020; Grandi, Bernasconi, 2020; Marques da Costa et al., 2021). For instance, the Johns Hopkins University was pioneer in representing the pandemic situation (Dong et al., 2020) with a recognizable semiology and a selected range of epidemiologicalcartographical datasets, at a point that that JHU dashboard turned out as a model for other cartographic solutions and became an official source of information at global level.

Although some critical issues were already pointed out with regard to the correctness of cartographic semiology (Juergens, 2020) and its real accessibility (Mooney, Juhász, 2020) in the context of pandemic monitoring, this trend did prove the general public's strong demand for health geography information (Kamel Boulos, Geragthy, 2020, Guallart Moreno, 2020), and the GIS approaches demonstrated to be promptly capable to catch the pandemic spatial trends in several different contexts, as well as to map them for an informed communication (Dangermond et al., 2020; Podda, Scanu, 2020; Marques da Costa et al., 2021). Nevertheless, the scarcity of granular data often prevented digital cartography to be adopted at the sub-national scale. This was particularly true for Italian Regions and Autonomous Provinces (Dai Prà et al., 2020).

\section{Case study}

The project concerned the territory of the Autonomous Province of Trento, a predominantly mountainous area located near the border between Italy and Austria.

The Province of Trento covers an area of $6,207 \mathrm{~km}^{2}$ and in 2020 had a population of 545,425 inhabitants. The central urban and traffic axis is the Adige Valley, which crosses the Province from north to south, and constitutes the main corridor for moving people and goods between Italy, Austria and Germany. Most of the population is located within the valley floor, with over $49.5 \%$ inhabitants 
residing below $250 \mathrm{~m}$ a.s.l. and just $18.9 \%$ settled above $750 \mathrm{~m}$ a.s.1..

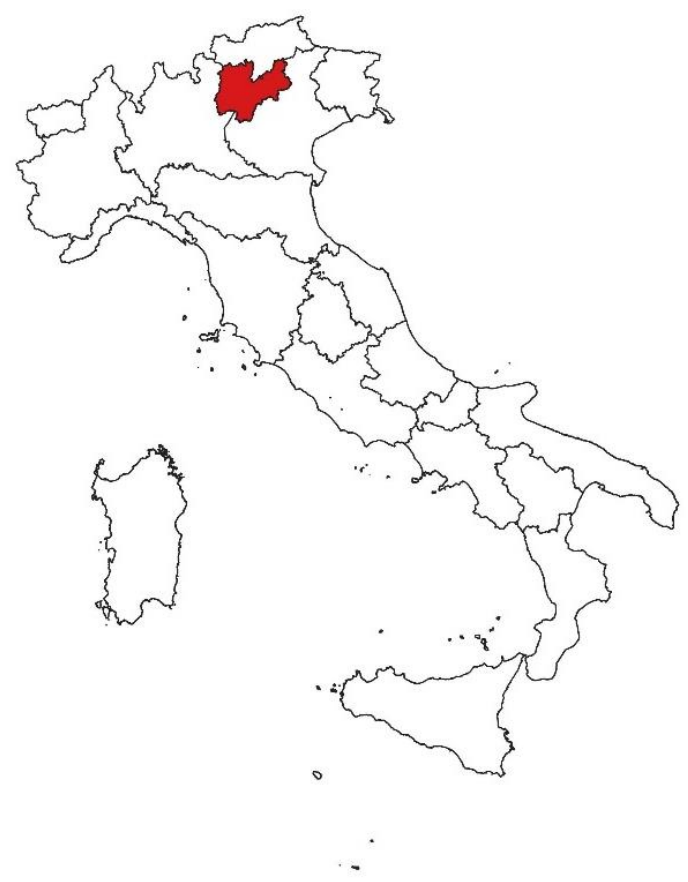

Figure 1. Localization of the Autonomous Province of Trento in Italy.

The Trento Province was among the first Italian territories affected by the COVID-19 pandemic, experiencing an important outbreak shortly after the identification of primary confirmed cases in Lombardy and Veneto; in particular, the first confirmed case was detected on March $2^{\text {nd }}, 2020$ in the provincial capital city, Trento. The increase in infections during the first weeks of March was rapid, and by the end of March almost all the municipalities have had infections.

Proximity to Lombardy, touristic flows, infra and inter regional commuting have been identified as the most influential factors to explain the dynamics of internal diffusion (Brunialti et al., 2020),

In order (1) to develop a new approach of digital cartographic representation of data at the largest possible scale for a better identification of epidemiological dynamics, and (2) to develop a tool for monitoring the health situation in Trentino, an Agreement between the Trento Autonomous Province Local Health Authority (APSS) and the Geo-cartographic Center of the University of Trento (GeCo) was signed. Within this framework, an interactive dashboard able to disseminate spatial epidemiological data concerning the Trentino territory among the public, was implemented. The WebGIS dashboard allows to widen the accessibility of municipality-scaled epidemiological datasets, as well as to improve the understanding of CoViD-19 trends for local citizens and communities.

\section{Data}

For the development and definition of the dashboard, it was necessary to consider the nature and structure of the available data, as well as their critical treatment. The acquisition of sources, and the integration of heterogeneous information, arose as a crucial problem that could be overcome by comparing them on a spatial basis.

The proliferation of datasets, even divergent ones, that took place during the months of lockdown, in fact strongly posed the problem of using complete and reliable sources, together with methodological questions about the available statistics.

This project was based on an exclusive use of official data produced by public bodies appointed to health management, namely the local Health Authority (APSS), which guarantees the reliability of the process of their production, and the constant respect for the confidentiality of patients' data. Indeed, by virtue of the status of autonomy guaranteed by Italian constitutional law, the Province of Trento was granted autonomous powers also in the healthcare management context. This results in the production of proven and homogeneous data, which guarantees that the local epidemiological dataset has a sufficient reliability and consistency for its cartographic spatial analysis (Torri et al. 2020).

APSS provided a dataset consisting of the official number of the infected, clinically recovered, deceased, with their age group. These data were aggregated day by day on a municipal basis, along a time interval spanning from March 2020 to May 2021. All the data were properly anonymized to ensure the protection of sensitive data. This dataset was processed and integrated with a GIS software, in order to develop a spatial database integrated with the polygonal layer of the Trentino municipalities: for the final cartographic result each typology of data was aggregated on a municipal scale, on a weekly basis.

\section{Methods}

\subsection{WebGIS architecture}

The system runs on a virtual machine containing both software and data.

For the realization of the WebGIS, the shapefile of the municipal boundaries of the Province of Trento was used as a reference vector and itnwas imported into a geographic database built using MySQL. MySQL is an open-source DBMS (Database Management Services), with native spatial components able to manage geographical data (Fig. 2). 
The WebGIS platform was created using open-source technologies and in particular Javscript language libraries, focused for rendering geographic data on desktop and mobile devices (ensuring the required responsiveness).

Data are provided by a geographic database and are converted "on-the-fly" into geojson standard interchange format. This file is read by the javascript scripts to produce the final maps.

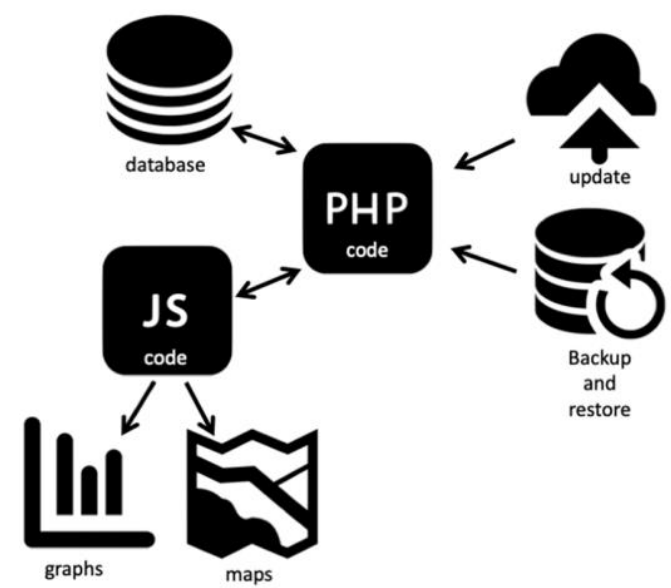

Figure 2. WebGIS and dashboard architecture and workflow.

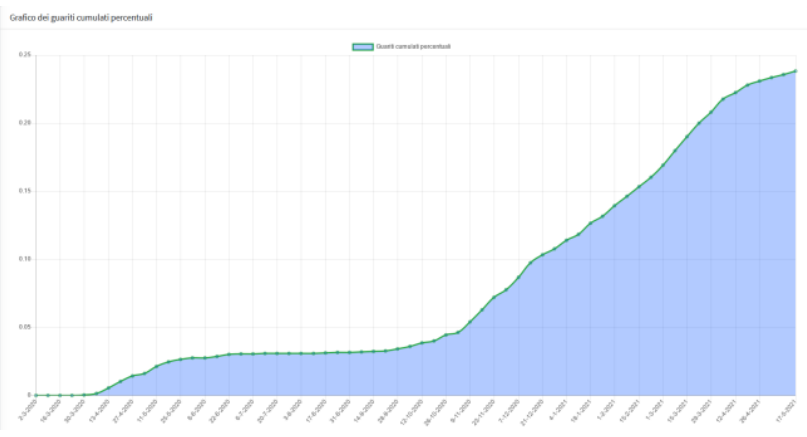

Figure 3. Example of interactive graph, showing the percentage of cases healed out of the total population.

For each map, specific scripts based on the chart.js library also produce the graph of the data temporal variation, automatically reading dates and time of analysis (Fig. 3).

The system automatically uses all the available data, as long as they fit in the database structure. While maps and graphs can be downloaded as images, the original data cannot be accessed by the WebGIS users, to safeguard the privacy of the patients.

Maps provided by the OpenStreetMap open-source service (OSM), a project born in 2004 as a free editable map of the world made by volunteers, were chosen as background maps. The tabular data were associated with the corresponding geographical elements using the unique municipal code field.

The database can be periodically updated by the WebGIS administrators through special import functions that allow to directly import the updated data using simple appropriately formatted Excel table, that are subsequently converted into a MySQL table. Automatic backup and restore functions also allow the site manager to restore a previous version of the database, in case of failure of the import process. All the update and restore functions are included in a reserved area accessible only by the WebGIS administrators.

\subsection{Dashboard management and visualization}

Grandi and Bernasconi (2020) analyzed 63 websites produced in various parts of the world and by different entities, devoted to the monitoring of the epidemic. According to their survey, the project presented here presents some specific elements, which make it a peculiar while not unique case: the representation of a provincial territory, with aggregated data on a municipal scale; the exclusive application of opensource software; the usage of official data collected and produced locally. Based on such data and other auxiliary demographic and social statistics, the indicators that make up the WebGIS are calculated. Such indicators (i.e., infections - or confirmed cases - per 100,000 population, by municipality) allows the assessment of the situation and the relations between the pandemic trends and the socio-demographic environment. At the present moment, on the basis of available statistics, available and mapped data for each municipality are:

- Weekly infections

- Weekly deaths

- Weekly recovered

- Weekly active cases

- Cumulative infections since the beginning of the pandemic (including recovered and deceased)

- Cumulative recovered

- Cumulative deaths

- The weekly proportion of infections detected within nursing facilities respect to the total confirmed cases of a given municipality

The proposed dashboard shows the daily absolute confirmed CoViD-19 cases, deaths and recovered for each municipality through a point map (Fig. 4), while the coropleth map displays the relative value of cumulative confirmed cases, deaths and recovered respect to the local population, as well as the weekly number of active cases. 


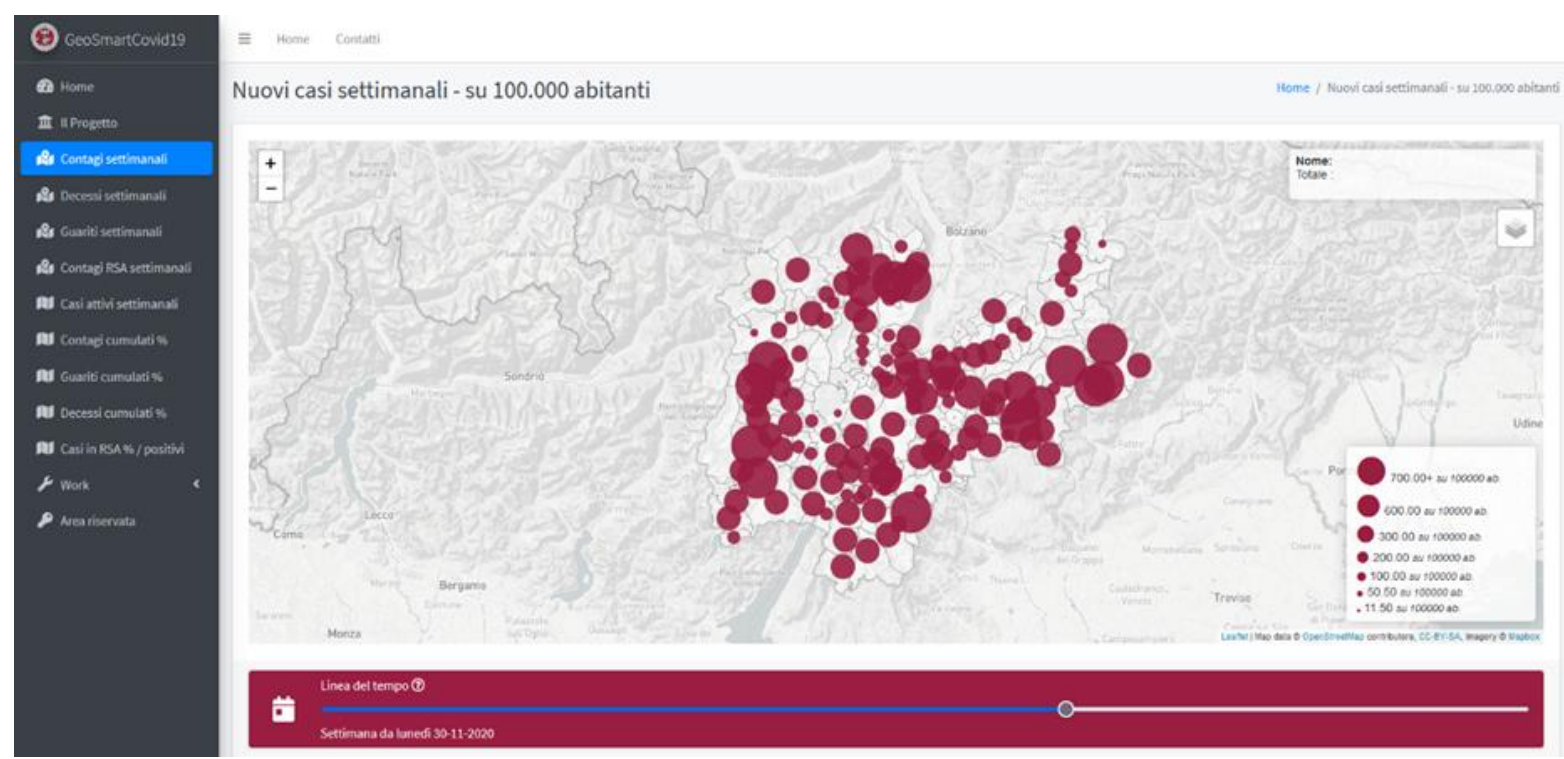

Figure 4 . The dashboard showing the weekly new confirmed cases vector dot map with timeline.

The user can query the map to obtain the cumulative data for each dataset and can also navigate throughout the series of weekly maps up to a specific date in the past.

The spreading of the epidemic is therefore shown progressively from March 2020 to May 2021, with the data of confirmed cases, deaths and recovered respect to the local population.

A limitation of this project is due to data availability, especially in order to safeguard patients' data confidentiality. In doing so, it has been necessary to omit some information, such as the municipality with an excessively low rate of weekly infections and deaths. In this case confidentiality is guaranteed by the extent of the lower numeric and chromatic class, that was properly calibrated to avoid any risk of identification.

As already mentioned, a timeline integrated in the dashboard allows users to check out the dynamics of virus propagation during time. In any case, the raw relative amount of people affected by CoViD-19 respect to total municipal population is shown using a range of colors associated to the administrative polygon vector layer, while absolute values are represented with variably sized centroids, and their variations can be enhanced through the interaction with the timeline to observe the occurrence of localized clusters, the permanence of enduring hotspots and so on.

\section{Outputs and perspectives}

The ongoing general project on the Geography of CoViD19 in Trento Province has a double aim: firstly, it has Public Geography purposes, namely, to disseminate the most advanced results of scientific studies to the general public; secondly, it could be also considered as an Applied Geography initiative, aimed at offering informative content to solve specific problems for territorial management. This distinction (Ward 2006) reflects the dual nature that should characterize the research outputs: in this case, working papers for an exegesis of the phenomenon to be provided to specialists and decision makers, and a website integrated with digital cartography for the communication to general public.

In this regard, the construction of cartographic series makes it possible to combine a synchronic and diachronic approach, configuring maps as a crucial heuristic tool for the representation and analysis of social, environmental and health data with important effects on local communities' empowerment.

Following this wake, we introduced a WebGIS dashboard for the monitoring and assessment of the pandemic trends within the Trento Autonomous Province. The interactive map is available at [covid19mappa-trentino.geco.unitn.it]. Spatial data can provide valuable information both for the general public and for public health managers on the epidemiological dynamics, such as areas more affected in specific periods of time, recovered concentrations and mortality rates. However, usual sources are typically limited to textual description or static maps and graphs, 


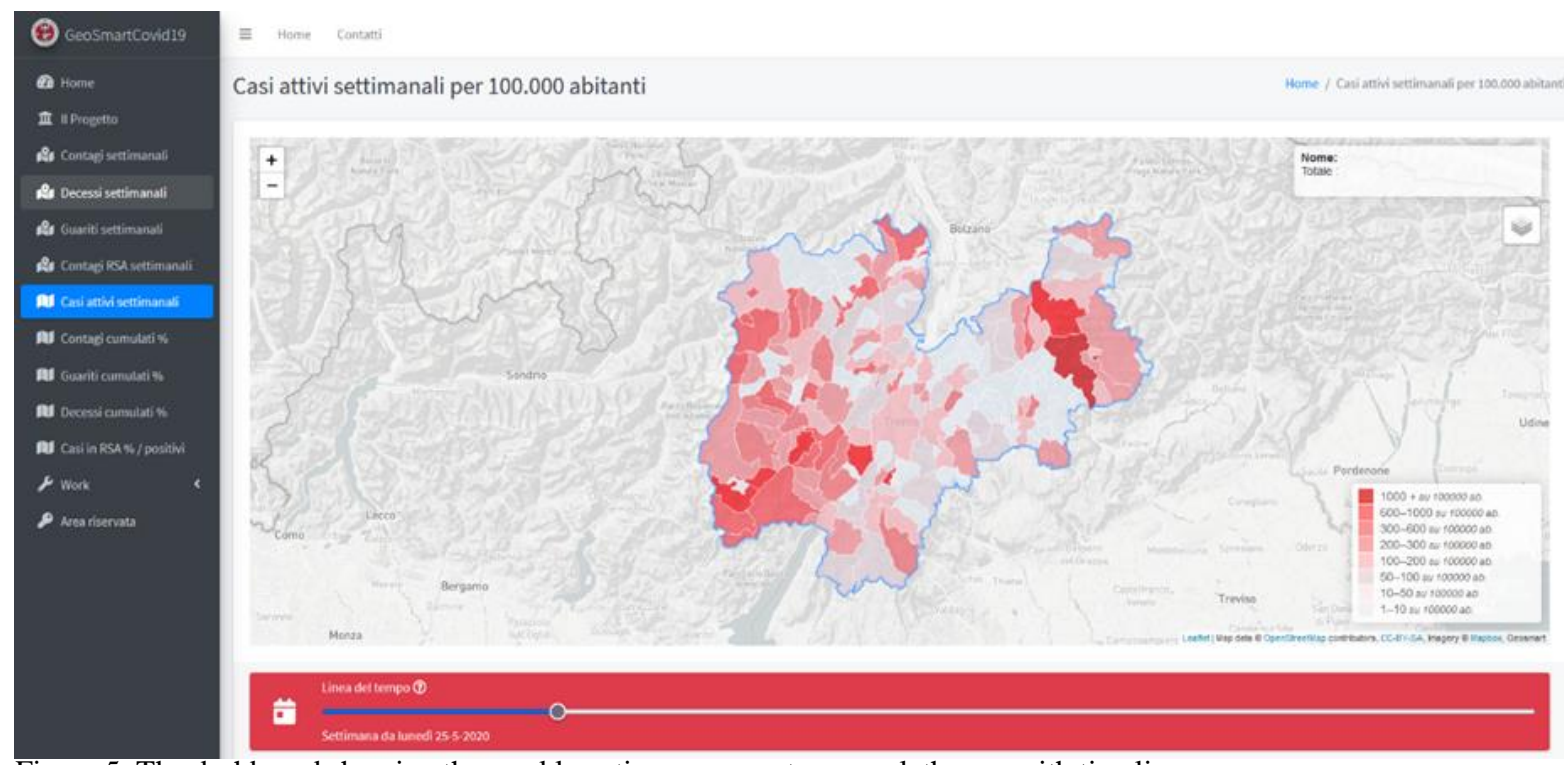

Figure 5. The dashboard showing the weekly active cases vector coropleth map with timeline.

based on the sole data that were available in the moment such products were issued.

The benefits of dynamic digital cartography have been clearly acknowledged by many researchers, and include the possibility to provide updated information, to reduce redundancy and to increase non-expert people accessibility to information (Howell et al., 2019).

Our interactive map relies upon first-hand official sanitary data collected and shared by the Local Health Authority and allows to assess CoViD-19 infection dynamics at the finest possible disaggregation level without engendering confidentiality issues. Data have been anonymized by aggregating the information spatially, merging data at the municipality level, and temporally, using a temporal resolution of one week. As the platform has been and will be continuously updated as long as the health dataflow is kept active, we hope that our product could be useful to reliably disseminate sanitary information not only to the local communities, but also to the researchers interested in studying the pandemic patterns at the local level.

In future, the WebGIS would be improved, in order to support the comparison between the epidemiological data and other sources of social and environmental statistics (Marques da Costa et al., 2021), to allow non-expert users to develop different data comparison for a better understanding of factors affecting the pandemic dynamics.

\section{Acknowledgements}

The authors acknowledge the members of the research group Elena Dai Prà, Angelo Besana and Tiziano Brunialti for their helpful comments.

\section{Funding}

This study was supported by the University of Trento, "Bando Strategico di Finanziamento COVID-19" 2020 Funding, GEO-SMART Grant. The funding entity had no involvement in the study design and realization.

\section{References}

Aitken, S.C. (2002), "Public participation, technological discourses and the scale of GIS, in: Craig W., Harris T., Weiner D. (editors), Community participation and geographic information systems, Taylor \& Francis, London, 357-366.

Arora, R.K., Joseph, A., Van Wyk, J., Rocco, S., Atmaja, A., May, E., Yan, T., Bobrovitz, N., Chevrier, J., Cheng, M.P., Williamson, T. Buckeridge, D.L. (2020), "SeroTracker: a global SARS-CoV-2 seroprevalence dashboard", The Lancet Infectious Diseases. https://doi.org/10.1016/S1473-3099(20)30631-9

Berry, I., Sooucy, J-P. R., Tulte, A., Fisman, D. (2020), "Open access epidemiologic data and an interactive dashboard to monitor the COVID-19 outbreak in Canada", The Canadian Medical Association Journal, 192(15), E420. https://doi.org/10.1503/cmaj.75262

Brunialti, T., Dai Prà, E., Gabellieri, N. (2020), "Malattie infettive e cartografia per l'analisi e il monitoraggio: il progetto di mappatura del COVID-19 in Trentino", Bollettino dell'Associazione Italiana di Cartografia, 170 Special Issue, 19-36. Doi: 10.13137/2282-572X/32254

Carroll, L.N., Au, A.P., Detwiler, L.T., Fu T.-C., Painter I.S. and Abernethy N.F. (2014), "Visualization and analytics tools for infectious disease epidemiology: A 
systematic review", Journal of Biomedical Informatics, 51, 287-298. http://dx.doi.org/10.1016/j.jbi.2014.04.006

Cope, M. and Elwood, S. (2009), Qualitative GIS: A Mixed Methods Approach, SAGE, London.

Crooks, V.A., Andrews, G.J., Pearce, J. (Eds, 2018), Routledge Handbook of Health Geography, Routledge, London.

Dagnino, R., Weber, E. Panitz, L. (2020). “Monitoramento do Coronavírus (Covid-19) nos municípios do Rio Grande do Sul, Brasil", SIG Litoral, Universidade Federal do Rio Grande do Sul. https://dataverse.harvard.edu/dataset.xhtml?persistentId =doi:10.7910/DVN/JK4STL

Dai Prà, E., Fornasari, C., Rapisarda, A. (2020), "Leggere e comunicare l'emergenza attraverso la cartografia: per un'analisi della trasmissione dei dati epidemiologici durante la pandemia COVID-19”, Bollettino dell'Associazione Italiana di Cartografia, 170 Special Issue, 4-18. Doi:10.13137/2282-572X/32253

Dangermond, J., De Vito, C. and Pesaresi, C. (2020). "Using GIS in the Time of the COVID-19 Crisis, casting a glance at the future. A joint discussion", J-Reading, 1(9), 195-205. Doi:10.4458/3099-16

Dong, E., Du, H. and Gardner, L. (2020), “An interactive web-based dashboard to track COVID-19 in real time", The Lancet Infectious Diseases, 20, 533-534. https://doi.org/10.1016/S1473-3099(20)30120-1

Dragićević, S. (2004), “The potential of Web-based GIS”, Journal of Geographical Systems, 6, 79-81.

Evangelidis, K., Agrianidis, A., Perakis, K., Papadopoulos, T., Papatheodorou, K. (2018), "Web-GIS development for geospatial data dissemination in EU operational programmes", European Journal of Geography, 9, 2, 21-36.

Few, S. (2006), Information Dashboard Design: The Efective Visual Communication of Data, O'Reilly Media: Boston.

Franch-Pardo, I., Napoletano, B.M., Rosete-Verges, F., Billa, L. (2020), "Spatial analysis and GIS in the study of COVID-19. A review", Science of the Total Environment, 739, w.p. https://doi.org/10.1016/j.scitotenv.2020.140033

Gao, S., Rao, J., Kang, Y., Liang, Y. and Kruse, J. (2020), "Mapping county-level mobility pattern changes in the United States in response to COVID-19", SIGSPATIAL Special, 12(1). https://doi.org/10.1145/3404820.3404824

Grandi, S., Bernasconi, A. (2020), “Convergenza di web design e informazione spaziale, statistica, genomica ed epidemiologica: il caso delle geo-dashboard nella crisi
COVID-19”, Documenti geografici, 1, 463-476. http://dx.doi.org/10.19246/docugeo22817549/202001_29

Grava, M. (2016), “imágenes estúpidas versus imágenes inteligentes. Empleo de WebGIS y Cloud service para la publicación de geo-datos", Revista Uruguaya de Historia Económica, VI, 9, 73-80.

Guallart Moreno C. (2020), "La Cartografía digital generada por la COVID-19: Análisis Y tipologías”, Espacio, Tiempo y Forma, 13, 103-134. http://dx.doi.org/10.5944/etfvi.13.2020.27806

Hohl, A., Delmelle, E.M., Desjardins, M.R. and Lan, Y. (2020). "Daily surveillance of COVID-19 using the prospective space-time scan statistic in the United States", Spatial and Spatio-temporal Epidemiology, 34. https://doi.org/10.1016/j.sste.2020.100354

Howell, R.G., Petersen, S.L., Balzotti, C.S., Rogers, P.C., Jackson, M.W., Hedrich, A.E. (2019), "Using WebGIS to Develop a Spatial Bibliography for Organizing, Mapping, and Disseminating Research Information: A Case Study of Quaking Aspen", Rangelands, 41, 6, 244247. https://doi.org/10.1016/j.rala.2019.10.001.

Juergens, C. (2020), "Trustworthy COVID-19 Mapping: Geo-spatial Data Literacy Aspects of Choropleth Maps", KN - Journal of Cartography and Geographic Information. https://doi.org/10.1007/s42489-020-00057W

Kamel Boulos, N.M., Geraghty, E.M. (2020), "Geographical tracking and mapping of coronavirus disease COVID-19/severe acute respiratory syndrome coronavirus 2 (SARS-CoV-2) epidemic and associated events around the world: how 21st century GIS technologies are supporting the global fight against outbreaks and epidemics", International Journal of Health Geography,

(19)8. https://doi.org/10.1186/s12942-020-00202-8

Lu, H., Stratton, C.W. and Tang, Y.-W. (2020), “Outbreak of pneumonia of unknown etiology in Wuhan, China: The mystery and the miracle", Journal of Medical Virology, 92, 401-402. https://doi.org/10.1002/jmv.25678

Marques da Costa, N., Mileu, N., Alves, A (2021), "Dashboard COMPRIME_COMPRI_MOv: Multiscalar Spatio-Temporal Monitoring of the COVID-19 Pandemic in Portugal", Future Internet, 13, 45, 1-17. https://doi.org/10.3390/fi1302004

Miller, H.J., Goodchild, M.F. (2015), “Data-driven geography”, GeoJournal, 80, 449-461. Doi:10.1007/s10708-014-9602-6 
Mooney, P., Juhász, L. (2020), "Mapping COVID-19: How web-based maps contribute to the infodemic", Dialogues in Human Geography, 10(2), 265-270. doi:10.1177/2043820620934926.

Palagiano, C. (1998), Geografia Medica, Carrocci, Milan.

Podda, C., Scanu, G. (2020), Trattamento spaziale dei dati pandemici: la cartografia del COVID-19, Bollettino dell'Associazione Italiana di Cartografia", 170 Special Issue, 37-57. Doi: 10.13137/2282-572X/32255

Torri, E., Sbrogiò, L.G., Rosa, E.D., Cinquetti, S., Francia, F., Ferro, A. (2020), "Italian Public Health Response to the COVID-19 Pandemic: Case Report from the Field, Insights and Challenges for the Department of Prevention", International Journal of Environmental Research and Public Health, 17, 10, s.p. https://doi.org/10.3390/ijerph17103666

Ward, K. (2006), “Geography and public policy: towards Public Geographies", Progress in Human Geography, 30, 495-503. https://doi.org/10.1191/0309132506ph621pr

WHO (2005), Outbreak communication guidelines, World Health Organization, Geneva. 